\title{
Thoracic spinal cord compression due to xtramedullary haemopoiesis in a patient with beta-thalassemia: complete clinical regression with radiation therapy alone
}

\author{
Aramita Saha' ${ }^{1}$, Subrata Chattopadhyay ${ }^{2}$, Md Azam $^{3}$, Koushik Chatterjee ${ }^{1}$ \\ ${ }^{1}$ Department of Radiation Oncology, IPGMER \& SSKM Hospital, Kolkata, India \\ ${ }^{2}$ Department of Radiation Oncology, North Bengal Medical College\& Hospital, Siliguri, India \\ ${ }^{3}$ Department of Radiation Oncology, Medical College, Kolkata, India
}

Received November 07, 2014; Revised December 06, 2014; Accepted December 067, 2014; Published Online December 07, 2014

\section{Case Report}

\begin{abstract}
Spinal cord compression due to extramedullary haemopoesis in beta-thalassemia is extremely rare. Controversies are there between the two modalities of treatment surgery vs radiation therapy. We present here a case of beta thalassemia major in a twenty one year old female patient who presented with features of spinal cord compression due to extramedullary haemopoesis. She was then treated with $3000 \mathrm{cGy}$ of radiation therapy targeted to the T5-T8 region, as $200 \mathrm{cGy} /$ fraction daily, 5 fractions/week, over 6 weeks. The patient's haemoglobin was elevated from $6.1 \mathrm{~g} / \mathrm{dl}$ to $10.1 \mathrm{~g} / \mathrm{dl}$, with her haematocrit rising from $26.3 \%$ to $32.8 \%$. Steroid dose was tapered on hospital day number 7. She achieved near full neurological recovery after medical treatment with steroids, blood transfusion and radiation therapy.
\end{abstract}

Keywords: Extramedullary Haemopoiesis; Spinal Cord Compression; Radiation Therapy; Thalassemia

\section{Introduction}

The thalassemia is congenital quantitative defect in hemoglobin synthesis. It produces normal hemoglobin but in reduced amounts. ${ }^{1}$ Extramedullary haematopoiesis (EMH) is a compensatory phenomenon commonly seen in the abdomen, chest, or epidural space. ${ }^{2,3}$ It occurs in thalassemia and myeloproliferative disorders, such as sickle cell anemia, polycythemia vera, chronic myelogenous leukemia. ${ }^{4}$ Incidence of EMH in Thalassemia is about $0.8 \% .^{5}$

EMH may form pseudotumors such as in the paravertebral region of the chest. EMH usually forms a soft, red mass resembling a hematoma on its cut surface. At histologic analysis, all hematopoietic elements are found in EMH. ${ }^{1}$

The diagnostic procedure of choice is Magnetic resonance imaging (MRI) which characteristically shows an isointense mass with a high spinal intensity rim on T1-weighted images and a hyperintense mass on T2-weighted images. ${ }^{6,7,8}$ Most authors do not favor a tissue biopsy in this situation. ${ }^{9}$ The onset of neurologic symptoms in a known patient of thalassemia should raise concern for cord or thecal sac compression by an EMH. ${ }^{10}$

The first documented cases of spinal cord compression from EMH was described by Gatto in 1954, based on clinical ex- amination and myelography. ${ }^{11}$ Treatment of spinal cord compression due to EMH may be radiation therapy to halt the production of overgrown marrow tissue, surgical decompression or a combination of both. ${ }^{2,12}$

We present here a case of Thalassemia with spinal cord compression due to extramedullary Haematopoesis in a twenty one year old female whose neurological symptoms recovered near completely with External beam radiotherapy. As far our best knowledge, the scenario we portrayed is extreme rarity.

\section{Case Presentation}

This 21-year-old female with characteristic facies, frontal bossing, prominent malar prominences with poor muscular development status post-splenectomy presented with 12-days history of worsening gait and leg weakness. Three months prior to presentation the patient reported a self-limited episode of low back pain. Two months after this episode she noted slipping of sandals from her feet, numbness and tingling sensation of feet and legs. Back pain was relieved by sitting or standing up exacerbated by sneezing, cough. She was diagnosed Beta Thalassemia major at the age of 7 years. 
HPLC revealed $\mathrm{HbF} 31.1 \%$ and $\mathrm{HbA2}$ 60.7\%. She was receiving blood transfusion frequently.

Physical examination was remarkable. Bilateral lower extremity showed decreased muscle tone, minimal left lower extremity weakness, bilateral ankle clonus, and 3+ patellar reflexes bilaterally. Gait testing demonstrated no truncal ataxia, however unsteadiness when standing was observed.

Initial haematological examination showed a haemoglobin level of $6.1 \mathrm{~g} / \mathrm{dl}$, PCV 26.2\%, MCV $83 \mathrm{fl}$, MCHC $26.3 \mathrm{~g} / \mathrm{dl}$, RBC count of $2.9 \times 106 / \mathrm{mm}^{3}$, WBC count of $8 \times 103 / \mathrm{mm}^{3}$, and platelet count of $2.8 \times 105 / \mathrm{mm}^{3}$. Serum biochemistry shows: Iron 138 g/ dl, Ferritin 375 ng/ml, Total iron binding capacity (TIBC) $187 \mu \mathrm{g} / \mathrm{dl}$, and Total Bilirubin $3.1 \mathrm{mg} / \mathrm{dl}$ (Unconjugated 2.2).

Chest X ray showed posterior mediastinal masses. CT scan of the chest revealed multiple lobulated paravertebral masses over the Thoracic spine with good contrast enhancement. CT guided FNAC showed Extramedullary haemopoiesis. MRI spine showed evidence of hypercellular marrow pattern in all the dorsal vertebrae and extensive lobulated margined paravertebral, prevertebral and posterior aspect of dorsal spinal canal lesions mainly at D5 to D8 levels. The lesions are isointense to muscle in $\mathrm{T} 1$ and hyperintense to STIR (Short T1 Inversion recovery). Adjacent spinal cord is compressed with associated dorsal myelopathy (Figure 1).

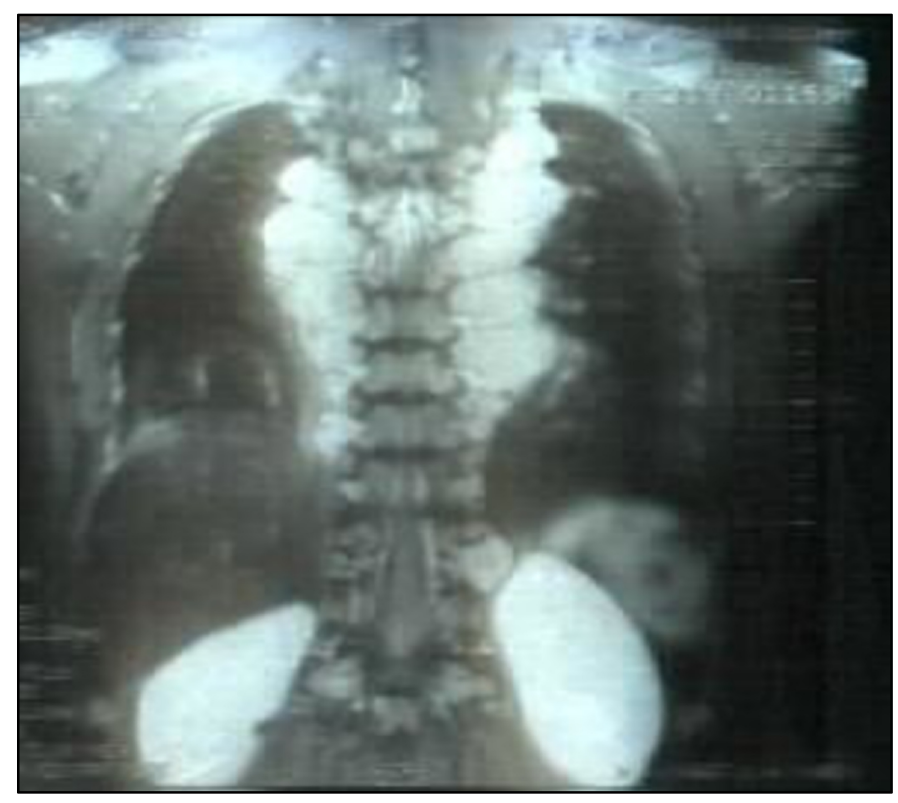

FIG.1: MRI of spine.

The patient was started on steroids and received blood transfusions. She was then treated with 3000 cGy of radiation therapy targeted to the T5-T8 region, as $200 \mathrm{cGy} /$ fraction daily, 5 fractions/week, over 6 weeks. The patient's hemoglobin was elevated from $6.1 \mathrm{~g} / \mathrm{dl}$ to $10.1 \mathrm{~g} / \mathrm{dl}$, with her haematocrit rising from $26.3 \%$ to $32.8 \%$. Steroid dose was tapered on hospital day number 7 . She achieved near full neurological recovery after medical treatment with steroids, blood transfusion and radiation therapy.

Follow up imaging of the thoracic spine was performed after 2 months which showed significant improvement of the epidural masses of mid thoracic spine.

\section{Discussion}

Hemopoietic tissue is extremely sensitive to radiation and low doses cause rapid shrinkage. Improvement is clinically evident after an average of 3-7 fractions of radiotherapy and near complete recovery is generally observed by the end of treat- ment. ${ }^{13}$ Doses used have ranged from 750-3500 cGy. ${ }^{8}$ With these low doses, the only significant toxicity that may occur is a further decrease in blood cell counts which need to be frequently monitored. ${ }^{12}$

Excellent results have been obtained in cord compression due to $\mathrm{EMH}$ in thalassemia with radiotherapy alone. Recurrence rates of about $19 \%$ have been reported but these cases are amenable to treatment with further radiation. ${ }^{8,14}$

Niggeman et al described a case for whom radiation therapy originally appeared effective, but who then experienced recurrence of symptoms after a short period, making an operative approach necessary. ${ }^{15}$ Most reported cases of paraplegia due to EMH from any cause have been treated with surgical decompression with or without radiation therapy. ${ }^{10}$ The bias towards surgery in these cases is due to its immediate decompressing effect. Some authors also believe that radiation therapy may cause initial worsening of symptoms due to tissue edema. But this problem can be easily addressed with 
concomitant steroid therapy. ${ }^{17}$ Munn RK in 1988 showed that treatment with steroids and external beam radiation is effective and usually long-lasting. ${ }^{8}$

The case reported by us revealed dramatic clinical as well as radiological improvement with radiation therapy in a twenty one year old female thalassemic patient who presented with spinal cord compression due to Extramedullary haematopoiesis.

\section{Conflict of interest}

The authors declare that they have no conflicts of interest. The authors alone are responsible for the content and writing of the paper.

\section{References}

1. Wintrobe MM, Greer JP. Wintrobe's Clinical hematology. $11^{\text {th }}$ ed. Philadelphia: Lippincott Williams \& Wilkins; 2004.

2. Issargisil S, Piankijagum A, Wasi P. Spinal cord compression in thalassemia. Report of 12 cases and recommendations for treatment. Arch Intern Med 1981; 141: 1033-6.

3. Lichtman MA, Williams WJ. Williams Hematology. $7^{\text {th }}$ ed. New York: McGraw-Hill Medical Pub. Division; 2006.

4. Meo A, Cassinerio E, Castelli R, et al. Effect of hydroxyurea on extramedullary haematopoiesis in thalassaemia intermedia: case reports and literature review. Int J Lab Hematol 2008; 30: 425-31.

5. Prabhakar S, Chopra JS, Khosla VK, et al. Spinal cord compression in homozygous beta thalassemia. Surg Neurol 1980, 13: 351-4.

6. Chehal A, Aoun E, Koussa S, et al. Hypertransfusion: a successful method of treatment in thalassemia intermedia patients with spinal cord compression secondary to extramedullary hematopoiesis. Spine 2003; 28: E245-9.

7. Khen-Dunlop N, Girot R, Brunelle F, et al. Surgical treatment of an unusual case of pelvic extramedullary hematopoiesis. J Pediatr Surg 2006; 41:e13-5.

8. Munn RK, Kramer CA, Arnold SM. Spinal cord compression due to extramedullary hematopoiesis in beta-thalassemia intermedia. Int J Radiat Oncol Biol Phys 1998; 42: 607-9.

9. Kaufmann T, Coleman M, Giardina P, Nisce LZ. The role of radiation therapy in the management of hematopoietic neurologic complications in thalassemia. Acta Haematol 1991; 85: 156-9.

10. Salehi SA, Koski T, Ondra SL. Spinal cord compression in beta-thalassemia: case report and review of the literature. Spinal Cord 2004; 42: 117-23.
11. Gatto I, Terrana V, Biondi L. Compression of the spinal cord due to proliferation of bone marrow in epidural space in a splenectomized person with Cooley's disease. Haematologica 1954; 38:61-75.

12. Lau SK, Chan CK, Chow YY. Cord compression due to extramedullary haemopoiesis in a patient with thalassemia. Spine 1994; 19: 2467-70.

13. Singhal S, Sharma S, Dixit S, et al. The role of radiation therapy in the management of spinal cord compression due to extramedullary hematopoiesis in thalassemia. J Neurol Neurosurg Psychiatry 1992; 55: 310-2.

14. Jackson DV Jr, Randall ME, Richards F. Spinal cord compression due to extramedullary hematopoiesis in thalassemia: long term follow up after radiotherapy. Surg Neurol 1988; 29:388-92.

15. Niggemann P, Krings T, Hans F, Thron A. Fifteen-year follow-up of a patient with beta thalassaemia and extramedullary haematopoietic tissue compressing the spinal cord. Neuroradiology 2005; 47: 263-6.

16. Papavasiliou C, Sandilos P. Effect of radiotherapy on symptoms due to heterotopic marrow in beta-thalassaemia. Lancet 1987; 1: 13-4.

17. Tan TC, Tsao J, Cheung FC. Extramedullary haemopoiesis in thalassemia intermedia presenting as paraplegia. J Clin Neurosci 2002; 9: 721-5. 